\title{
Comic and Dynamics of Its Political Applications
}

\section{Olena Pavlova}

Doctor of Philosophical Sciences, Professor, Taras Shevchenko National University of Kyiv (Kyiv, Ukraine)

E-mail: invinover19@gmail.com

https://orcid.org/0000-0002-0593-1336

The paper is devoted to the analysis of the variability of historical forms of comic, in particular the specifics of the organization of contextual socio-cultural practices and the appropriate way of the syndication. For this angle of study, reference is made to the works of modern British scholar Scott Lash, who substantiates the methodological connection of the cultural paradigm and the signification mode. The comparison is made out of the specifics of the organization of a comic in the conditions of the ancient Greek policy and modern Ukrainian politics.

Postmodern synthesis of political comic and administration of horror testifies to a new level of cultural de-differentiation, and is a symbol of the end of the social. The horror of the total chaos of personified corruption highlights the ironic evidence of their political scheme and the comic populism of their representations. Unlike the comic of Antiquity, where theatrical satire was a way of social criticism of political leaders, and, consequently, a way of increasing meaning, the comic populism of post-modernity is a way of concealing the disappearance of meaning. Although both historical versions of the interaction of political and comic work in the logic of the sign.

The analysis of Ukrainian situation has its own specific of the synthesis of political comic and administration of horror.

Keywords: comic, politics, differentiation, signification mod, cultural practice, Ukraine, Ancient Greek comedy

Received: February 5, 2019; accepted: March 13, 2019

Ukrainian Policymaker, Volume 4, 2019: 36-42.

https://doi.org/10.29202/up/4/6

\section{Introduction}

The problem of cultural practices organization is the basic in the contemporary humanitarian discourse. Even sociology, through turning to the problems of everyday life and material, goes into the field of sociology of culture and even "cultural sociology" [Lamont, 2000]. An important step in this way, in our opinion, was the works of the British researcher Scott Lash [Lash, 2013]. It demonstrates the logic of the relationship between the degree of cultural differentiation and the signification mod. This concept is the basic methodological orientation of our research.

(C) Pavlova, Olena, 2019 


\section{De-differentiation of early forms of culture and separation of ridiculous laughter}

The first historical form of feeling unity was a total non-differentiation of horror and pleasure such as a fascination. In this context, the emergence of laughter can be considered as an indicator of a degree of differentiation, as the contemporary researchers of animal psychology pointed out. The beast's grin, which was a symptom of intimidation, through disappearance of danger and humanization of emotions marked with the state of relief and detente therefore, turns into laughter.

The complex form of syncretism with a certain shift towards a slight differentiation, is described by modern scholars in such terms as "festive laughter" [Bakhtin, 1984: 12], "precomical laughter" [Freidenberg, 1998: 68], "ritual laughter" [Propp, 2009: 131]. ${ }^{1}$ At the same time, the totality of the aesthetic experience in the situation of hierofany corresponded with the "liberation from a hindrance to the vital force" [Kant, 2006: 154], "bliss" (in the words of G. Hegel) [Hegel, 1975: 1200] and at the same time contains the potential for rebirth and regeneration. The ritual involved the unity of meaning in the dynamics of various signs. Russian structuralist Vladimir Propp defined and analyzed forms "the comic of similarity" and "the comic of difference" such as "comic of food," "comic of drinking," "comic of intoxication," "comic of the body," "comic of the smell" [Propp, 2009: 36]. Here, various signifiers of a funny acted as a common attribute of the ritual of maintaining fertility, which became the basis for the Neolithic. Metaphorical archaic culture demonstrated the common sense in the process of diversifying the signifiers.

Consequently, the signification mod of symbolism is carried out through the similarity of signifiers, but with the possibility of a certain semantic shift. Ontological unity of cultural practices (production - consumption - pleasure) could not be carried out directly in the process of its own differentiation, and therefore required a new medium and the reorganization of the signifiers order in new cultural practices according to the logic of the medium itself. The separation of the comic effect could serve as a rate of the gap between the sacred and the profane, the signified and the signifier, the subject and the object.

The differentiation between the sacred and the profane had its extension in the following forms of distinction of the subject-object opposition, in particular, in the emergence of "ridiculous laughter" [Propp, 2009: 11]. The latter is laughable in the narrow sense of the term, according to Marina Rumina [Rumina, 2010: 320]. Ridiculous laughter necessarily has a certain object of mocking, ridiculing. The next step in the process of differentiation was actually the comic.

\section{The policy and the specifics of the Ancient Greek comedy}

An integral part of this process was the emergence of art as a secular form of sacred and, accordingly, comic as an artistic form of the laughable. The Comic as an embodiment of ridiculous laughter had its object of embodiment and certain mimetic techniques of its realization (comic similarity, comic of double characters). Comic situation as a unit of analysis meant "the presence of components unity that could not be separated" [Rumina, 2010: 81], but at the same time certain situation (in particular, comic) became possible only as a profanation

${ }^{1}$ Interesting in this context is the fact that all the proposed terms were formulated by Russian researchers in the mid-twentieth century, which was a period of dynamic and complex period. 
of the ritual totality. Comic situation was the rate of the sign discreteness that fell from the unity of the sacred action in measure of profanization. In the process of religion emerging, the sacred content became a serious and a sublime, and laughter became profaned (not without de-differentiations, of course). Comic as a profanation form of laughable tended to private, mundane and daily. However, at the same time, the aesthetic potential of mimesis preserved the signification mod of symbolism, where various signifiers pointed to the unity and sacredness of sense. However, the mimesis as the meaning of the ritual likening to the divine in measure of profane transformed into an artistic method, the means.

If the sacred totality did not require external similarity due to the similarity of signifiers (for example, architecture as the embodiment of the structure of the world order), the comical situation then necessarily anticipated some measure of similarity. Thus, the logic of imagery began to form, where the presence of the referent became obligatory attribute. Consequently, comic mimesis was separated from the hierophany manifestation of archaic culture. The prophan revealed the similarity of the signifiers emphasizing the shift of meaning, its growth in the logic of social criticism and the politicization of social action. The heirophany represented a dynamics of signifiers, the row of which revealed the common sacredness of the world. Diversification of meaning emphasized the external similarity of signifiers in the reduction of inviolability of the authority of the common good. Thus, the signification mod of symbolism was replaced by the sign dominant.

Comic mimesis was not only a way of deforming and profaning sacred, but at the same time contained the potential for its regeneration and purification, catharsis in new artistic way. "But the comical rests as such throughout on contradictory contrasts both between aims in themselves and also between their objects and the accidents of character and external circumstances, and therefore the comic action requires a solution almost more stringently than a tragic one does. In a comic action the contradiction between what is absolutely true and its realization in individuals is posed more profoundly" [Hegel, 1975: 1200].

Therefore, satire in Antiquity was the first and foremost political phenomena of city-state and had not only a descriptive, but also a perlocative task (therefore the generalization of characters in comedies after Aristophanes testified to the superiority of artistic content over the political one). The absence of a clear distinction in premodern political structures, that was, a clear differentiation between legislative and executive judicial powers, contributed to such a form of collective reflection as an antique theater and its comic form of critique of atypicalness and wrongness of social action. No wonder Aristotle formulates the classification of the right and wrong states. Where cultural practices of the ritual could not cope with the chaos of social deviations, new ordering forms of cultural experience came. Wilhelm Hegel wrote: "the comical as such implies an infinite light-heartedness and confidence felt by someone raised altogether above his own inner contradiction and not bitter or miserable in it at all: this is the bliss and ease of a man who, being sure of himself, can bear the frustration of his aims and achievements" [Hegel, 1975: 1200].

The theater was for the ancient culture to replace the integrity of the ritual and turned it into a spectacle that had already been fixed in the etymology of the term. This meant that most of the participants in the theatrical action turned into immovable spectators. Thus, there was an opportunity if not perspective, but constant point of view, decoration and dramatic text, fragments of which we can examine and read nowadays.

The similarity of comic signifiers emphasized the difference in contexts and, accordingly, signified which were the derivatives. The multiplicity of contexts suggested common signifiers 
pointing to each other. Thus, cultural phenomena began to work in the logic of sign. The degree of similarity between signifiers in the signification mod of a sign is much higher than in symbol, but less than in requirements for the organization of the image.

\section{The Political and the Comic in a de-differentiation situation}

Modern as an extreme degree of differentiation cultivated the artistic form of irony as a reflexive distance from all the trivialities of everyday life. "So also was its contrary, aesthetic distance, which does not consist in the ecstatic contemplation of the beautiful and thereby work mischievously to conceal the social underpinnings of art and dispense with concrete action in the 'outside' world. Instead, it was first used to refer to the suspension of a determinable relation between the artist's intention, a performance in some place reserved for art, and the spectator's gaze and state of the community. This is, after all, what 'critique' means: separation" - wrote Jacques Rancière [Rancière, 2010: 137]. Accordingly, the autonomy of art represented in the absolutisation of the logic of the image and accordingly signification mod. The postmodern tendency towards the de-differentiation of all cultural forms regenerating the "trans-aestheticization," in the formulation of Jean Baudrillard, reveals "the conspiracy of art" in this way and hence the mimetic origins and modernist and postmodernist signification mods of comic.

The Trickster character of many political figures in postmodern politics becomes obvious and is not limited to a single national framework. In particular, it becomes apparent in the situation of de-differentiation of the executive, legislative and judicial powers and even mediapower. In particular, the contemporary corruption dominant in politics corresponds to the nonmodern stage of the anomie, that is, a deviation from the norm, which can be reversed under a certain algorithm of sanctions and legal decisions. This state of affairs suggests that the corruption chaos of the system become a new "system" of chaos and produces an according way of signifiers organizing. Numerous reforms of the law-enforcement system and other anticorruption measures designed to bring the Ukrainian society to a normal state of affairs, testify to the failure of any.

The other side of the successful strategy absence of a legal stabilization, which was typical of the high modernity, is the decline in the growth of political ideas. The symptom of this state of affairs is the lack of ideological fullness of political slogans, but only the existence of the names of politicians who repeat the mantra of corruption exorcism and appeals for the observance of the democracy values. However, the instrumental nature of their using serves to draw attention to the implementation of their "fifteen minutes of fame", in order to timely attract attention during the election period. Electorate knows the price of spells, but besides them there are no options in the situation of post-democracy. Therefore, it remains to vote for who is the best in performing the ritual of promises. Behavior becomes not political, but magical, however now it is not about raining, but the returning to the dyeing out welfare state.

Infinite repetition of phrases, which have become ritual, but also rhetorical, becomes the dominant way of signifiers organizing and gets comical meaning. This regeneration of the comic of doubling characters (as well as tripleting, and so on to infinity), as well as comic similarity has happen. The similarity of all exhortations to pre-election programs excludes any basic of the principle of identification. "Carnivalesque travesty" [Bakhtin, 1984: 14] dominates. Comical seriousness is an ambivalent to serious comedy. 
However, at the same time, documentary accuracy of contemporary political discourse substitutes cause-effect relationships that can be reflected. Modern political tends to be unconscious consciously. In comparison with the theatrical satire of the Antiquity, it is characterized by reversal tendency to the disappearance of meaning, and, consequently, by the significance diminution of the relations of the signifiers and the signifieds, and therefore, by the emphasizing the relationships of signifiers. Numerous media replicate populist rhetoric and allow it to function in different contexts. Thus, the comic effect of the latter is generated. The collage-organization of media hyperbolizes the disappearance of meaning, which also works to eliminate the claim to the norm and increase the comic effect.

If in the unity of hierophany the language as a sign structure had not had autonomy in relation to the crucible of cultural practice, in theatrical satire the similarity of the signifiers emphasized the contrast with the various contexts, thus the sign structure of the comic situation dominated under other ways of interpreting discourse. This thing repeats under the postmodern circumstances of reducing the meaning of discursive practices. In the presence of a civil society, the interpretation and play of the signifier and the signified had a dominant meaning, that is, the predominant dynamic of meaning having influenced the organization of signifiers. In the logic of de-differentiation the reverse tendency prevails.

Discursive practices from the sphere of the text in a postmodern situation are displaced in a visual series, as Roland Barthes's "rhetoric of the image" already showed [Barthes, 1977: 70-74]. The idea differs from the media content as a camel from the trade route. The design of a certain content in the structure of images retains although the possibility and even conflict of interpretations, however the multi-vectorness of interoperating is reduced. Therefore, with the comical seriousness of the usual politicians and their pseudo-alternatives, the alternative of a frankly comic character in a political event accumulates the meaning of potential protest and, at the same time, the ways of its frittering, but not an alternative to the growth of meaning as such.

Printed signs become a companion to the picture with a categorical requirement to reduce the number of letters. There are too much letters - the classic formulation. The inscription is compressed to the size of the comment, SMS. Thus, not only the sense changes, but also the meaning is superseded. Appeal to the exaggeration of emotions is a logical result of the absence of semantic shifts in the political sphere. However, these are emotions, but not feelings. A claim of the comic to the logic of the sign, that is, on the game of the signifier and the signified, turns into a pastiche, that is, to ironic indifference without a claim to the norm. Deviations of deviations make total chaos. Such an intense dynamics of images causes not having time to give birth for reflexing the meaning. A similar situation is characterized by Jean Baudrillard: "Thus, there's no more passion in politics. There's only an apathy, and one on the other side to play on words-a compassion" [Baudrillard, 2005:149]. French thinker said that "Reality, in general, is too obvious to be true" [Baudrillard, 2005: 167]. The indifference of the pastiche is the most obvious guideline of post-modernity and its hyper-realism. It makes everything so transparent in the vision mode of obviousness, which thus leads to the hope that not everything can be so one-dimensional in this polyfunctional world.

Comic tricks can be used by certain politicians with the purpose of discrediting their opponents during the election. Then, breaking out of the context of separated statements and images. The absolutisation of subtexts again forces political imagery to work in the logic of signs. However, in the absence of political ideas, the exchange of signs highlights the intensification of the circulation of signifiers. So, instead of criticizing the political program (under circumstance of their absence at both "opponents") one side creates a photo-shopping 
on another one. In response, ten of them have appeared. The other sides are responding to the first series that numbers of photo-shopping are growing up and increase the pseudo-political swamp at the whole. The circulation of comically organized signifiers imitates the availability of meaning and political communication.

Hyperrealism of the information age is drowning and dissolving discrete signs in the waves of media-flows. "The Implosion of Meaning in the Media" carries it out [Baudrillard, 2012]. We need very serious media strategies to ensure that a single wave of broadcasting has a fairly elucidation and stability. The predominant role here, first of all, plays not the successful role of a separate performance, but the ability to hold it on the apex. Therefore, the particular comic situation is not significant in the shadow of ironic obviousness. Only flow of information and entertainment with comical formation signifiers can be successful.

At the same time, the superficial effect of populism (which means "democracy that avenges its own failure" [Nancy, 2019]) is intended to conceal the deep horror of everyday life. Thus, the administration of horror (P. Virillo) [Virillo, 2007] and comic populism, which is the reverse side of the latter, are two factors in the dynamics of signifiers in the political sphere. The total loss of criticism and the claim to illusory nature is an indicator not only of the artistic sphere, but also of political importance, and therefore the question remains to Baudrillard's question to the political sphere.

At the same time, the superficial effect of populism is intended to conceal the deep horror of everyday life. Thus, the administration of horror (P. Virillo) and populist comicism, which is the reverse side of the latter, are two factors in the dynamics of signs in political sphere. The total loss of criticism and the pretension to illusory resolution of contradiction is an indicator not only of the artistic sphere, but also of political one, and therefore the Baudrillard's statement remains to the political sphere: "Images Where There is Nothing to See. There lies the dilemma: either simulation is irreversible, there is no going beyond simulation, it is no longer even an event, it is our absolute banality, it is an everyday obscenity, we are in terminal nihilism, and are preparing ourselves for a mindless repetition of all the forms of our culture, waiting for an unpredictable event — but where would it come from? Or there is an art of simulation, an ironic quality that resuscitates the appearances of the world each time to destroy them. Otherwise art would do nothing more, as it often does today, than work over its own corpse" [Baudrillard, 2005:118]. This Baudrillard's statement is osculant to the joke: ninety-eight percent of Russian telephone conversations do not contain important information, according to the FSB.

In general, it suggests that politics and art (and other autonomous spheres of culture and social institutions) having lost their specificity and autonomy, dissolve in the crucible of nondifferentiated cultural practices, where the transformation of some forms into the others has the character of the Trickster's mischief, rather than the pathos of struggle for the value of a high culture.

\section{Conclusions}

This analysis is just an attempt to outline correlations between the political and the comic and them link with the signification mod in historical perspective. Separating ridiculous laughter was one of the primary ways to capture an object through the separation of comic situations. Differentiation of sacred and profane led to the artistic design of the comic in the ancient drama. It was a form of correction of the political in the absence of organizational means. 
Postmodern synthesis of political comic and administration of horror testifies to a new level of cultural de-differentiation, and is a symbol of the end of the social. The horror of the total chaos of personified corruption highlights the ironic evidence of their political scheme and the comic populism of their representations. Unlike the comic of Antiquity, where theatrical satire was a way of social criticism of political leaders, and, consequently, a way of increasing meaning, the comic populism of post-modernity is a way of concealing the disappearance of meaning. Although both historical versions of the interaction of political and comic work in the logic of the sign.

\section{매] References}

Barthes, Roland. Rhetoric of the Image. New York: Hill and Wang, Noonday, 1977. https:// faculty.georgetown.edu/irvinem/theory/Barthes-Rhetoric-of-the-image-ex.pdf

Bakhtin, Mikhail. Rabelais and His World. Indiana University Press Bloomington, 1984.

Baudrillard, Jean. The Conspiracy of Art. London: The MIT Pres, Cambridge, 2005.

Baudrillard, Jean. The Implosion of Meaning in the Media. 2012. http://postmodernismandbaudrillard.blogspot.com/2012/01/baudrillard-implosion-of-meaning-in.html

Freidenberg, Olga. The Myth and Literature of Antiquity. Moscow: Eastern literature, 1998.

Hegel, Wilhelm Friedrich. Aesthetics. Lectures on Fine Art. Volume II. Oxford University Press, 1975.

Kant, Immanuel. Anthropology from a Pragmatic Point of View. Cambridge University Press, 2006.

Lamont, 'ele Michele and 'Evenot, Laurent. Rethinking Comparative Cultural Sociology. Cambridge University Press, 2000. https://pdfs.semanticscholar.org/4f20/13017c94cd$14498 \mathrm{cfb} 8 \mathrm{~b} 626 \mathrm{f} 76705 \mathrm{~b} 530 \mathrm{abe} . \mathrm{pdf}$

Lash, Scott. The Sociology of Postmodernism. Routledge, 2013.

Nancy, Jean-Luc. Populism, Democracy, and Neofascism: Two Essys. 2019. https://lareviewofbooks.org/article/populism-democracy-and-neofascism-two-essays/?fbclid=IwAR1HdrE47AVL3-q7J0T4JvK3dv15EcVQ0NDmwigxPua5zhCtv-POT8u4hHs\#

Propp, Vladimir. On the Comic and Laughter. University of Toronto Press, 2009.

Rancière, Jacques. Dissensus: On Politics and Aesthetics. Continuum, 2010.

Rumina, Marina. Aesthetics of laughter: Laughter as a virtual reality. Moscow, Librokom Press. 2010.

Virillo P. The Administration of Fear. Los Angeles: Semiotext(e), 2007. 